\title{
Effects of posture on flow-volume curves during normocapnia and hypercapnia in patients with obstructive sleep apnoea
}

First Department of Internal Medicine, Tohoku University School of Medicine, 1-1 Seiryo-machi, Aoba-ku, Sendai 980, Japan

C Miura

W Hida

H Miki

Y Kikuchi

T Chonan

T Takishima

Reprint requests to: Professor T Takishima

Accepted 15 February 1992

\author{
Chiharu Miura, Wataru Hida, Hiroshi Miki, Yoshihiro Kikuchi, Tatsuya Chonan, \\ Tamotsu Takishima
}

\begin{abstract}
Background A high ratio of forced expiratory to forced inspiratory maximal flow at $50 \%$ of vital capacity $\left(\mathbf{F E F}_{50} /\right.$ FIF $_{50}$ ) may identify upper airway dysfunction. Since hypercapnia increases the motor activity of airway dilating muscles its effects on the maximum expiratory and inspiratory flow-volume curves (MEIFV) in patients with obstructive sleep apnoea and in normal subjects in different postures was studied. Methods The effects of posture on the maximum expiratory and inspiratory flow-volume curves during the breathing of air and $7 \%$ carbon dioxide in 11 patients with obstructive sleep apnoea were compared with those in nine normal subjects. Measurements were made in the sitting, supine, and right lateral recumbent positions. Forced expiratory flow at $50 \%$ vital capacity $\left(\mathbf{F E F}_{50}\right)$, forced inspiratory flow at $50 \%$ vital capacity $\left(\right.$ FIF $\left._{50}\right)$ and $F E F_{50} /$ FIF $_{50}$ were determined. Results In the normal subjects FEF $_{50}$, FIF $_{50}$, and FEF $_{50} /$ FIF $_{50}$ were not affected by change in posture or by breathing carbon dioxide. In the patients there was a fall in FIF $_{50}$ and an increase in FEF $_{50}$ FIF $_{50}$ when breathing air in the supine position compared with values in the seated and lateral position. While they were breathing carbon dioxide there was a slight increase in $\mathbf{F E F}_{50}$ when patients were seated or in the lateral position compared with values during air breathing. Hypercapnia abolished the effects of posture on $\mathrm{FEF}_{50} / \mathrm{FIF}_{50}$. Values for $\mathrm{FEF}_{50} /$ FIF $_{50}$ in the supine position while they were breathing air correlated with the apnoeic index but not with other polysomnographic data.

Conclusion In patients with obstructive sleep apnoea the upper airway is prone to collapse during inspiration when the patient is supine, even when awake; this tendency can be reversed by breathing carbon dioxide.
\end{abstract}

Patients with obstructive sleep apnoea have episodic obstruction of the upper airway during sleep..$^{1-4}$ The maximum expiratory and inspiratory flow-volume curve (MEIFV) shows two abnormalities related to upper air- way dysfunction. A "saw tooth" configuration on the expiratory or inspiratory flow, or both is thought to be due to pharyngeal fluttering whereas a high ratio of forced expiratory maximal flow at $50 \%$ of vital capacity to forced inspiratory maximal flow at $50 \%$ of vital capacity $\left(\mathrm{FEF}_{50} / \mathrm{FIF}_{50}\right)$ may identify upper airway obstruction. ${ }^{6}$

In one report on patients with obstructive sleep apnoea $\mathrm{FEF}_{50} / \mathrm{FIF}_{50}$ was greater in the supine position than the seated position. Upper airway resistance is greater in the supine than the sitting posture. ${ }^{8}$ Thus in patients with obstructive sleep apnoea the upper airway is less able to remain patent during inspiration when the patient is supine, even when awake. Since hypercapnia increases the motor neurone activity of the upper airway dilating muscles ${ }^{9}$ and decreases upper airway resistance ${ }^{10}$ it may increase maximal flow, particularly inspiratory flow, in the supine position. The first purpose of this study was to determine whether hypercapnia influences the effects of posture on MEIFV curves in patients with obstructive sleep apnoea and normal subjects.

Episodes of obstructive apnoea depend on the posture assumed during sleep, being more frequent in the supine than the lateral position. ${ }^{11}{ }^{12}$ The degree of upper airway obstruction estimated from the MEIFV curve in the supine position may therefore correlate better with obstructive apnoeic episodes than do estimates from measurements made in other postures. Our second purpose therefore was to examine the relation between the data obtained from MEIFV curves in the supine position and polysomnographic data in patients with obstructive sleep apnoea.

\section{Methods}

SUBJECTS

Eleven patients (10 men, one woman) with obstructive sleep apnoea and nine normal men were studied. The table shows the anthropometric data. There were no significant differences in age, height, or weight between the two groups. All patients had a history of snoring and excessive daytime sleepiness, and five complained of morning headache. Four patients had hypertrophy of the palatopharyngeal fold with narrowing of the pharnygeal lumen. No other anatomical abnormalities 
Anthropometric and spirometric data and ventilatory response to hypercapnia in normal subjects and patients with sleep apnoea syndrome. Values are means ( $S E$ )

\begin{tabular}{|c|c|c|c|c|c|c|c|c|}
\hline & $\begin{array}{l}\text { No of } \\
\text { subjects }\end{array}$ & Age (years) & Height $(\mathrm{cm})$ & $\begin{array}{l}\text { Weight } \\
\text { (\% predicted) }\end{array}$ & $\begin{array}{l}V C \\
\text { (\% predicted) }\end{array}$ & $F E V_{t} / V C(\%)$ & $\begin{array}{l}\triangle \dot{V}_{E} / \triangle P E T C O_{2} \\
(\mathrm{l} / \mathrm{min} / \mathrm{mm} \mathrm{Hg})\end{array}$ & $\begin{array}{l}\Delta P_{0.1} / \triangle P E T C O_{2} \\
\left(\mathrm{~cm} \mathrm{H}_{2} \mathrm{O} / \mathrm{mm} \mathrm{Hg}\right)\end{array}$ \\
\hline $\begin{array}{l}\text { Normal } \\
\text { subjects } \\
\text { Patients }\end{array}$ & $\begin{array}{r}9 \\
11\end{array}$ & $\begin{array}{ll}43.6 & (2.9) \\
51.6 & (2.7)\end{array}$ & $\begin{array}{ll}168 & (2) \\
161 & (2)\end{array}$ & $\begin{array}{ll}103 & (5) \\
118 & (6)\end{array}$ & $\begin{array}{ll}113.9 & (4.0) \\
101.7 & (6.0)\end{array}$ & $\begin{array}{ll}82 \cdot 6 & (2 \cdot 5) \\
84 \cdot 1 & (2 \cdot 0)\end{array}$ & $\begin{array}{ll}1.80 & (0.28) \\
1.94 & (0.16)\end{array}$ & $\begin{array}{ll}0.42 & (0.02) \\
0.46 & (0.08)\end{array}$ \\
\hline
\end{tabular}

VC, slow vital capacity; $\mathrm{FEV}_{1} / \mathrm{VC}$, forced expiratory volume in one second divided by $\mathrm{VC} ; \dot{V}_{\mathrm{E}}$, minute ventilation; $\mathrm{P}_{0.1}$, mouth pressure 0.1 second after onset of an occluded inspiration; $\mathrm{PETCO}_{2}$, end tidal carbon dioxide tension.

were identified. Written informed consent was obtained from each subject before the start of the experiments.

\section{FLOW-VOLUME CURVES}

Slow vital capacity and forced vital capacity in one second $\left(\mathrm{FEV}_{1}\right)$ were measured with a spirometer (Benedict-Roth 13.5-L spirometer, Tatebe Seishudo, Tokyo, Japan). After 15 minutes MEIFV curves were measured with a direct writing flow-volume recorder (Chest, Tokyo, Japan) ${ }^{13}$ in the sitting, supine, and right lateral recumbent positions in a random fashion while subjects were breathing air (normocapnia) and in hypercapnia. MEIFV curves during hypercapnia were obtained after the breathing of $7 \%$ carbon dioxide in oxygen for five minutes with a nonbreathing circuit. The breathing circuit of the flow volume recorder was filled with $7 \%$ carbon dioxide in oxygen. At least two flowvolume curves were obtained for each posture, and the one with higher expiratory and inspiratory flows was used for analysis. Ten minutes elapsed between the two trials. Subjects were coached to avoid volume leaks at the mouthpiece, and care was taken to keep the head, neck, and trunk configuration as constant as possible in the three postures. ${ }^{14}$ Subjects were taught to avoid neck flexion and extension and to use maximal expiratory and inspiratory effort in all postures.

Four indices were derived from accepted flow-volume curves: firstly, presence or absence of a "saw tooth" configuration, which was defined as three or more consecutive peaks and troughs occurring at regular intervals and not exceeding $300 \mathrm{ml}$ during the middle half of the vital capacity in expiration, inspiration, or both'; secondly, forced expiratory flow at $50 \%$ vital capacity $\left(\mathrm{FEF}_{50}\right)$; thirdly, forced inspiratory flow at $50 \%$ vital capacity $\left(\mathrm{FIF}_{50}\right)$; and, fourthly, the ratio of $F F_{50}$ to $F F_{50}$ $\left(\mathrm{FEF}_{50} / \mathrm{FIF}_{50}\right)$.

VENTILATORY RESPONSE TO HYPERCAPNIA

Ventilatory response to hypercapnia was assessed by rebreathing $7 \%$ carbon dioxide in oxygen. Each subject wore a noseclip and breathed through a mouthpiece connected to a carbon dioxide rebreathing circuit. ${ }^{15}$ Minute ventilation ( $\dot{V} E)$ and mouth pressure $0 \cdot 1$ seconds after the onset of an occluded inspiration $\left(\mathbf{P}_{0.1}\right)$ were plotted against end tidal carbon dioxide tension $\left(\mathrm{PETCO}_{2}\right)$ and analysed by linear regression. The slopes of the two regressions $\left(\Delta \dot{\mathrm{VE}} / \Delta \mathrm{PeTCO}_{2}, \quad \Delta \mathrm{P}_{0.1} / \Delta \mathrm{PETCO}_{2}\right)$ were used as indices of the ventilatory response to hypercapnia.

\section{POLYSOMNOGRAPHY}

All patients were studied at least twice by standard polysomnographic techniques, including electroencephalography, electrooculography, monitoring of respiratory cage movement, and electrocardiography. ${ }^{16}$ Respiratory movements of the rib cage and abdomen with tidal volume summation were measured by inductive plethysmography (Respitrace, Ambulatory Monitoring, Ardsley, New York, United States). Arterial oxygen saturation was measured continuously with a pulse oximeter (Biox 3700, Ohmeda, Boulder, Colorado, United States). Airflow at the nose and mouth was recorded with two thermistors. Tracheal sounds were detected with a microphone attached to the skin over the trachea and were band pass filtered (200 to $1000 \mathrm{~Hz}$ ), rectified, and integrated to display the sound envelope. ${ }^{1718}$ All variables were recorded continuously on a polygraph (Model 360, NEC San-ei, Tokyo, Japan) and data recorder (A-109: Sony, Japan). Data from the second night were used in the analysis to avoid the first night effect. ${ }^{19}$

Apnoea was defined as the stopping of airflow at the nose and mouth and of breath sound at the trachea for longer than 10 seconds. ${ }^{16}$ Obstructive apnoea was identified as an absence of airflow signals despite continuing thoracoabdominal movement (Respitrace), and central apnoea as stopping of airflow signals with complete absence of thoracoabdominal movements. ${ }^{16}$

\section{DATA ANALYSIS}

Data from normal subjects and patients with obstructive sleep apnoea were compared by unpaired Student's $t$ test, and matched paired data within each group by paired Student's $t$ test. Correlation coefficients were calculated by linear regression analysis and linear regression by the least squares method. Values of $p$ below 0.05 were considered significant (two tailed test). Data are expressed as means and standard errors of the mean (SE).

\section{Results}

Spirometric data and ventilatory response to hypercapnia are summarised in the table. The slow vital capacity (VC) and $F E V_{1} / V C$ in the patients with obstructive sleep apnoea were within the normal range and did not differ from 


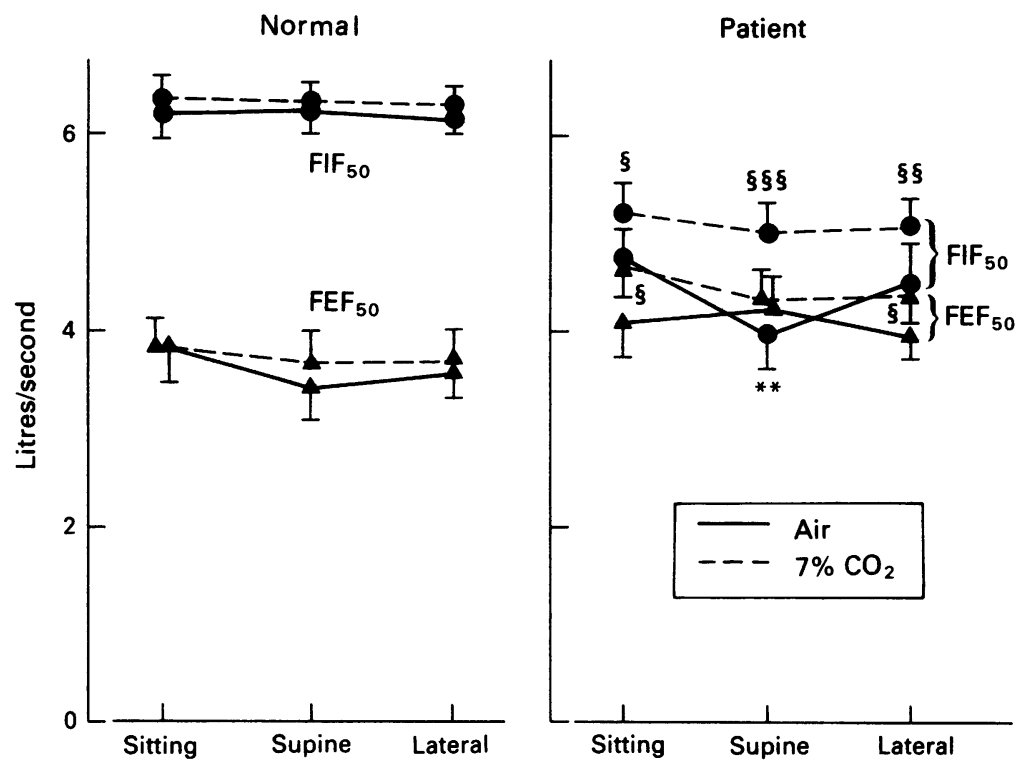

Figure 1 Effects of posture on forced expiratory ( $\mathbf{\Delta}$ ) and inspiratory ( $)$ flow rate at $50 \%$ of vital capacity during breathing of air (continuous line) and $7 \%$ carbon dioxide (dashed line) in normal subjects (left) and in patients with obstructive sleep apnoea (right). ${ }^{\star \star} p<0.01$ compared with sitting and lateral positions; $\$ p<0.05$, $\$ p<0.01, \$ \$ p<0.001$ compared with corresponding values during air breathing. Bars show $S E$ of mean. (suggesting extrathoracic obstruction) in four patients when seated and in seven when supine. The $\mathrm{FEF}_{50} / \mathrm{FIF}_{50}$ was not significantly different in the lateral and sitting posture during normocapnia. During hypercapnia the $\mathrm{FEF}_{50}$ FIF $_{50}$ in the supine position decreased to values seen in the sitting and lateral position. FEF $_{50}$ FIF $_{50}$ did not differ between normocapnia and hypercapnia in either sitting or lateral postures. $\mathrm{FEF}_{50} / \mathrm{FIF}_{50}$ was significantly greater in patients than in normal subjects.

Ventilatory responses to hypercapnia did not differ significantly between patients and normal subjects (table) and were similar to control values. ${ }^{15}$

There was a significant correlation between $\mathrm{FEF}_{50} / \mathrm{FIF}_{50}$ in the supine position and the apnoea index (apnoeic episodes per hour) but no correlation between $\mathrm{FEF}_{50} / \mathrm{FIF}_{50}$ and longest duration of apnoea or lowest arterial oxygen saturation overnight (fig 3). The $\mathrm{FEF}_{50}$ FIF $_{50}$ values in the sitting and lateral positions did not significantly correlate with the polysomnographic data. $\mathrm{FEF}_{50}$ and $\mathrm{FIF}_{50}$ in any posture did not correlate significantly with polysomnographic data or percentage of ideal body weight.

\section{Discussion}

We compared maximum flow values measured from flow-volume curves from normal subjects and patients with obstructive sleep apnoea in different postures and under hypercapnic stimulation. $\mathrm{FEF}_{50}, \mathrm{FIF}_{50}$, and $\mathrm{FEF}_{50} / \mathrm{FIF}_{50}$ were not affected by posture during normocapnia or hypercapnia in normal subjects. During normocapnia the $\mathrm{FEF}_{50} / \mathrm{FIF}_{50}$ in patients was there any differences in either measurement between hypercapnia and normocapnia.

The $\mathrm{FEF}_{50}$ in patients did not significantly differ from that in the normal group for any posture during normocapnia or hypercapnia. $\mathrm{FEF}_{50}$ was significantly higher, however, during hypercapnia when patients were in the sitting and lateral postures compared with the corresponding values during normocapnia. The IIF $_{50}$ was significantly lower in the supine position than values in the other two positions during normocapnia, and the $\mathrm{FIF}_{50}$ in all three positions was significantly higher during hypercapnia than during normocapnia; this was most noticeable in the supine position. The FIF $_{50}$ was significantly lower in patients than in the normal subjects for all postures during both normocapnia and hypercapnia.

A saw tooth configuration was observed in only four obese patients (body weight 120$150 \%$ of ideal) and was seen in both expiratory and inspiratory flows. The saw tooth shape was not affected by posture or hypercapnia.

Figure 2 shows the mean (SE) values for $\mathrm{FEF}_{50} / \mathrm{FIF}_{50}$ during normocapnia and hypercapnia in patients and normal subjects. In the normal subjects there were no significant differences in $\mathrm{FEF}_{50} / \mathrm{FIF}_{50}$ between the three postures and between normocapnia and hypercapnia in each posture. During normocapnia $\mathrm{FEF}_{50} / \mathrm{FIF}_{50}$ in patients was significantly greater in the supine than in the sitting and lateral postures, with values exceeding one

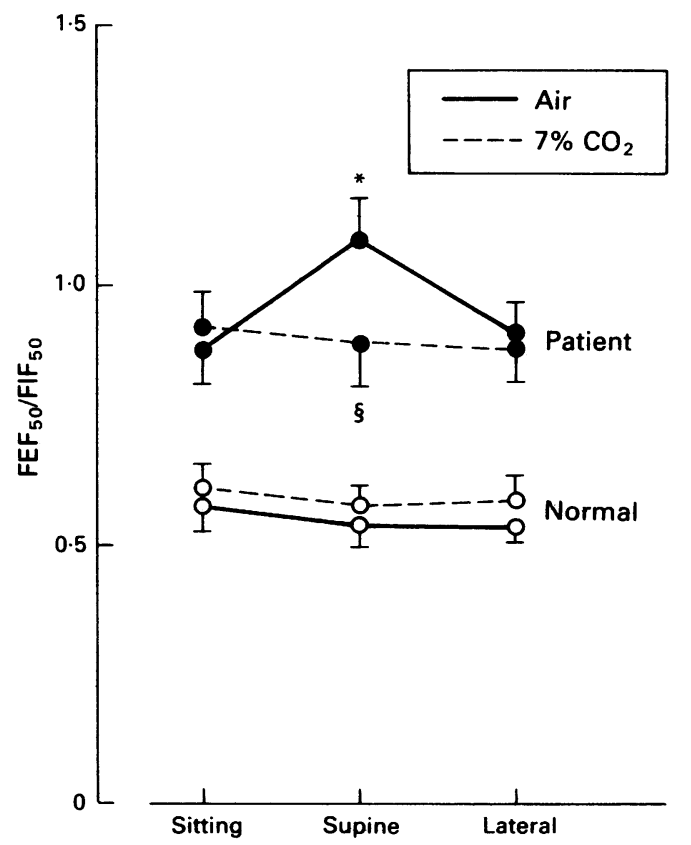
flow to forced inspiratory flow at $50 \%$ of vital capacity $\left(F E F_{s o} / F I F_{s o}\right)$ during breathing of air (continuous line) and $7 \%$ carbon dioxide (dashed line) in normal subjects (O) and in patients with obstructive sleep apnoea (O). ${ }^{\star} p<0.05$ compared with sitting and lateral positions; $\$ p<0.05$ compared with corresponding values during air breathing. Bars show $S E$ of mean.
Figure 2 Postural effects on ratio of forced expiratory 


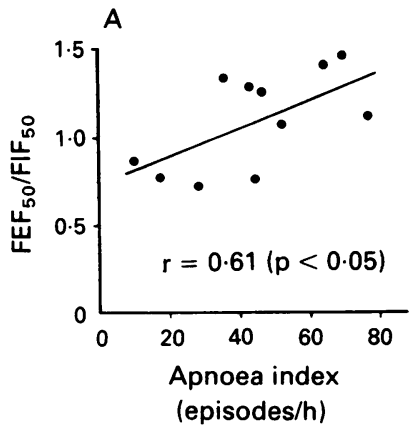

B

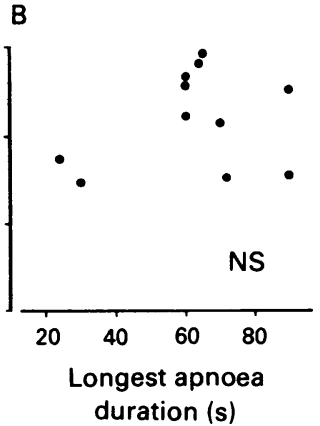

C

Figure 3 Relations between ratio of expiratory flow to inspiratory flow at $50 \%$ of vital capacity $\left(F E F_{s o} / F I F_{s o}\right)$ in supine posture during normocapnia and polysomnographic data in patients with obstructive sleep apnoea. occurred when the patients adopted a supine posture may be caused by movement of mobile soft tissues, such as the tongue and soft palate, towards the posterior pharyngeal wall or by an increase in mucosal and submucosal thickness due to vascular congestion. ${ }^{8}$ Hypercapnia increased both expiratory and inspiratory flow and abolished the effects of posture on $\mathrm{FEF}_{50} /$ FIF $_{50}$. The mechanism governing the effect of carbon dioxide on the flow-volume curve is not clear. One possible explanation is that hypercapnia is helping to maintain upper airway patency during forced inspiration, either indirectly by stimulating respiratory control through central and peripheral chemoreceptors or directly by stimulating upper airway muscles. ${ }^{910}$ Alternatively, hypercapnia may affect alertness and eliminate drowsiness by inducing an arousal response and increasing upper airway dilating muscle activity, resulting in upper airway dilation in the supine posture.

All flow-volume curves were measured while the subjects were awake. The observation concerning hypercapnic effects on upper airway muscle activity therefore may not be applicable to patients when asleep. In patients with obstructive sleep apnoea during sleep, not only the arousal response to hypercapnia or hypoxia, or both, ${ }^{24} 25$ but the negative intraoesophageal pressure during each frustrated inspiration of an obstructed episode is a powerful stimulus to breathe. $^{26}$

The value of the flow-volume curve in the diagnosis of obstructive sleep apnoea is controversial. $^{727-29}$ Although several authors have reported that the flow-volume curve was related to upper airway dysfunction in patients with obstructive sleep apnoea, ${ }^{72} 28$ recent studies suggest that the flow-volume curve is not useful in the diagnosis of obstructive sleep apnoea. ${ }^{29}$ We found that the $\mathrm{FEF}_{50} / \mathrm{FIF}_{50}$ during normocapnia in the supine posture correlated with apnoeic episodes. This measurement in awake patients might be useful in predicting apnoeic episodes in patients with obstructive sleep apnoea, as suggested previously. ${ }^{727}$ As the saw tooth appearance was not affected by posture or by breathing carbon dioxide it may not be specific for obstructive sleep apnoea.

In summary, we studied maximum expiratory and inspiratory flow-volume curves during both normocapnia and hypercapnia in normal subjects and patients with obstructive sleep apnoea. Our findings show that the upper airway in patients with obstructive sleep apnoea is less able to remain patent during inspiration when the patient is supine, even when awake, and this tendency can be reversed by breathing carbon dioxide.

We thank Dr R Scott for help in preparation of the manuscript.

1 Guilleminault C, Cumminskey J, Dement WC. Sleep apnea syndrome: recent advances. In: Stollerman $G H$, ed. Advances in internal medicine. Vol 26. Chicago: Year Book Medical Publishers, 1980:347-72.

2 Remmers JE, de Groot WJ, Sauerland EK, Anch AM. Pathogenesis of upper airway occlusion during sleep. Pathogenesis of upper airway
$J$ Appl Physiol 1978;44:931-8.

3 Suratt PM, McTier RF, Wilhoit SC. Collapsibility of the nasopharyngeal airway in obstructive sleep apnea. $A m R e v$ Respir Dis 1985;132:967-71.

The fall in maximum inspiratory flow that 
4 Issa FG, Sullivan C. Upper airway closing pressure in obstructive sleep apnea. J Appl Physiol 1984;57:520-7.

5 Saunders MH, Martin RJ, Pennock BE, Rogers RM. The detection of sleep apnea in the awake patients: the "sawtooth" sign. JAMA 1981;245:2414-8.

6 Miller RD, Hyatt RE. Evaluation of obstruction lesions of the trachea and larynx by flow-volume loops. Am Rev Respir Dis 1973;108:475-81.

7 Shore ET, Millman RP. Abnormalities in the flow-volume loop in obstructive sleep apnoea sitting and supine. Thorax 1984;39:775-9.

8 Anch AM, Remmers JE, Bunce III H. Supraglottic airway resistance in normal subjects and patients with occlusive sleep apnea. J Appl Physiol 1982;53:1158-63.

9 Bruce EN, Mitra J, Cherniack NS. Central and peripheral chemoreceptor inputs to phrenic and hypoglossal motoneurons. J Appl Physiol 1982;53:1504-11.

10 Miki H, Hida W, Kikuchi Y, Shindoh Y, Chonan T, Inoue H, Takishima T. Pressure flow relation of upper airway during loaded breathing in anesthetized dogs. Am Rev Respir Dis 1986;133:A377.

11 Mcevoy RD, Sharp DJ, Thornton AT. The effects of posture on obstructive sleep apnea. Am Rev Respir Dis 1986; 133:662-6.

12 Miki H, Hida W, Kikuchi Y, Takishima T. Effect of sleep position on obstructive sleep apnea. Tohoku J Exp Med 1988;156(suppl):143-9.

13 Takishima T, Sasaki T, Takahashi K, Sasaki H, Nakamura $T$. Direct writing recorder of the flow-volume curve and its clinical application. Chest 1972;61:262-6.

14 Castile R, Mead J, Jackson A, Mary EW, Stokes D. Effects of posture on flow-volume curve configuration in normal humans. J Appl Physiol 1982;53:1175-83.

15 Hida W, Susuki R, Kikuchi Y, Shindoh C, Chonan T, Sasaki $\mathrm{H}$, et al. Effects of local vibration on ventilatory response to
hypercapnia in normal subjects. Bull Eur Physiopathol Respir 1987;23:227-32.

16 Miki H, Hida W, Chonan T, Kikuchi Y, Takishima T. Effects of submental electrical stimulation during sleep on upper airway patency in patients with obstructive sleep apnea. Am Rev Respir Dis 1989;140:1285-9.

17 Krumpe PE, Cummiskey JM. Use of laryngeal sound recordings to monitor apnea. Am Rev Respir Dis 1980;122: 797-801.

18 Hida W, Miki H, Kikuchi Y, Miura C, Iwase N, Shimizu Y, et al. Home sleep monitor for detecting apnea episodes by nasal flow and tracheal sound recordings. Tohoku J Exp Med 1988;156(suppl):137-42.

19 Agnew HW Jr, Webb WB, Williams RL. The first night effect: an EEG study of sleep. Psychophysiology 1966;2: 263-6.

20 Melissinos CG, Mead J. Maximum expiratory flow changes induced by longitudinal tension on trachea in normal subjects. J Appl Physiol 1977;43:537-44.

21 Dawson SV, Elliott EA Wave-speed limitation on expiratory flow-a unifying concept. J Appl Physiol 1977; 43:498-515.

22 Stradling JR, Crosby JH. Predictors and prevalence of obstructive sleep apnoea and snoring in 1001 middle aged men. Thorax 1991;46:85-90.

23 Rodarte JR, Hyatt RE. Effect of acute exposure to $\mathrm{CO} 2$ on lung mechanics in normal man. Respir Physiol 1973;17: lung mech.

24 Berthon-Jones $M$, Sullivan $C E$. Ventilatory and arousal response to hypoxia in sleeping humans. Am Rev Respir Dis 1982;125:632-9.

25 Berthon-Jones M, Sullivan CE. Ventilation and arousal responses to hypercapnia in normal sleeping humans. J Appl Physiol 1984;54:59-67.

26 Gleeson $\mathrm{K}$, Zwillich $\mathrm{CW}$, White DP. The influence of increasing ventilatory effort on arousal from sleep. $A m R e$ Respir Dis 1990;142:295-300.

27 Haponik EF, Bleecker ER, Allen RP, Smith PL, Kaplan J Abnormal inspiratory flow-volume curves in patients with sleep-disordered breathing. Am Rev Respir Dis 1981;124: $571-4$.

28 Tammelin BR, Wilson AF, Borowiecki BDB, Sassin JF. Flow-volume curves reflect pharyngeal airway abnormalities in sleep apnea syndrome. Am Rev Respir Dis 1983 128:712-5.

29 Hoffstein V, Wright S, Zamel N. Flow-volume curves in snoring patients with and without obstructive sleep apnea. Am Rev Respir Dis 1989;139:957-60. 